Check for updates

Cite this: RSC Adv., 2018, 8, 3512

\title{
Rifaximin, a pregnane $X$ receptor (PXR) activator regulates apoptosis in a murine model of breast cancer
}

\author{
Swetlana Gautam, ${ }^{a}$ Priyanka Singh, ${ }^{a}$ Manjari Singh, ${ }^{a}$ Subhadeep Roy, ${ }^{a}$ \\ Jitendra K. Rawat, ${ }^{a}$ Rajnish K. Yadav, ${ }^{a}$ Uma Devi, ${ }^{b}$ Pushpraj S. Gupta, \\ Shubhini A. Saraf ${ }^{a}$ and Gaurav Kaithwas (D)*a
}

\begin{abstract}
The present study was proposed to investigate the effect of rifaximin (RFX) on methyl nitrosourea (MNU) induced mammary gland carcinoma in albino wistar rats. Animals were randomized and divided among four groups of six animals each. Group I (control $0.9 \%$ normal saline, $3 \mathrm{ml} \mathrm{kg}^{-1}$, p.o.); Group II (toxic control, MNU $47 \mathrm{mg} \mathrm{kg}^{-1}$, i.v.); Group III (RFX, $25 \mathrm{mg} \mathrm{kg}^{-1}$, p.o.); Group IV (RFX, $50 \mathrm{mg} \mathrm{kg}^{-1}$, p.o.). Toxicity was induced by single i.v. injection of MNU. MNU treatment was evident with increased alveolar bud count, differentiation score, up-regulated inflammatory enzyme markers (COX, LOX, NO and $\mathrm{H}_{2} \mathrm{~S}$ ) and oxidative stress markers (TBAR's, protein carbonyl, SOD, catalase and Ach). The mammary gland surface architecture was studied using SEM, carmine staining and H\&E staining. The treatment with RFX elicited noticeable restoration of the overall histological architecture in the experimental animals similar to the control. In the MNU treated toxic group, the levels of oxidative stress markers significantly increased in comparison to the control, which was subsequently restored after RFX treatment. Furthermore, RFX up regulated the levels of caspase 3 and caspase 8 , when compared to the MNU treated animals. MNU associated toxicity was also ascertained, when determined for UCHL-1, COX, NF$\kappa \mathrm{Bp} 65, \mathrm{BAD}$, and BCL-xl expression, while RFX demonstrated modulation of the same.
\end{abstract}

Received 31st August 2017

Accepted 5th January 2018

DOI: $10.1039 / c 7 r a 09689 e$

rsc.li/rsc-advances
PXR is a ligand dependent transcription factor known to regulate xenobiotic and cholesterol metabolism, energy homeostasis, gut mucosal defence and cancer development. Initially, the expression of PXR was reported to be highly tissue specific in liver and intestine..$^{4-7}$ Later, studies endorsed the PXR expression in mouse kidney, ovary, uterus, human brain and breast tissues. ${ }^{7-10}$ PXR has also been reported to be highly expressed in certain cancers and promote cell proliferation and chemoresistance, ${ }^{11-13}$ and potentially contributing to malignancy. ${ }^{12}$ Moreover, PXR overexpression by stable transfection of hPXR or by pharmacological activation has been reported to inhibit apoptosis in HepG2 cells. ${ }^{14}$ On the same line, overexpressing constitutively activated PXR or through pharmacological activation by rifampicin has been reported to proproliferative and anti-apoptotic in HCT116 (human colon cancer) and LS180 (intestinal human colon adenocarcinoma) cells. ${ }^{15}$ The studies have given an overall impression of proproliferative and anti-apoptotic role of PXR. However, PXR has also been shown to favourably regulate apoptosis, particularly in the tissues that are outside the metabolic realm of the liver and intestine, including tumour tissues of endometrial and breast cancer. ${ }^{16,17}$

A recent in vitro study has also proposed PXR as a novel mediator of apoptosis via p53-dependent and independent pathways. Ectopic expression of human PXR via stable 
transfection significantly inhibited the growth and cell proliferation in vitro, suggesting a novel physiological role of PXR in protecting the cells from unregulated oncogenic proliferation. ${ }^{\mathbf{1 6}}$ On the same line, Verma and colleagues ${ }^{\mathbf{1 8}}$ reported the inhibition of cell proliferation in the MCF-7 and ZR-75-1 breast cancer cells through structurally and functionally distinct PXR activators. The study also reported that the proliferative inhibition is mediated through cell cycle arrest at the G1/S phase followed by apoptosis mediated through the up-regulated pro-apoptotic genes, CDKN1A (p21), BBC3 (PUMA) and BAX. ${ }^{18}$ Henceforth, role of PXR, as pro- or anti-apoptotic in breast cancers stands as an important aspect for optimizing breast cancer therapies. The above aspect of PXR activators is further strengthened by the fact that most of the commonly used chemotherapeutic agents (e.g. tamoxifen, taxol, cyclophosphamide, cisplatin) are PXR activators and requires further investigation using appropriate in vivo systems. Considering the above the present study was undertaken to elaborate the effect of RFX (PXR activator) on cellular proliferation and apoptosis against $\mathrm{N}$-methyl nitrosourea (MNU) induced mammary gland carcinoma.

\section{Materials and methods}

\section{Drug and chemicals}

RFX was procured from Lupin Limited, Mumbai, India. MNU was obtained from Sigma Aldrich Co. St. Louise Mo 63103 USA. The fluorometric assay kits for the estimation of caspase 3 (SC4263) and caspase 8 (SC-4267) were purchased from Santacruz biotechnology Inc., California, Delaware. All other chemicals were of analytical grade and procured from Genetix Asia Private Limited, New Delhi else otherwise stated in the text.

\section{Experimental protocol}

Albino wistar female rats of 100-120 g body weight were used for this study. The rats were procured from the central animal house facility. The animals housed in polypropylene cages under controlled conditions ( $12 \mathrm{~h}$ light/dark cycle), with a free access to a standard pellet diet and water ad libitum. They were acclimatized for a period of two weeks prior to the commencement of the experiment. Animals were randomized and divided into 4 groups of 6 animals each. Group I (control 0.9\% normal saline, $3 \mathrm{ml}$ $\mathrm{kg}^{-1}$, p.o.); Group II (toxic control, MNU $47 \mathrm{mg} \mathrm{kg}^{-1}$, i.v.); Group III (RFX, $25 \mathrm{mg} \mathrm{kg}^{-1}$, p.o.); Group IV (RFX, $50 \mathrm{mg} \mathrm{kg}^{-1}$, p.o.). Toxicity was induced by single i.v. injection of MNU followed by RFX therapy for 90 days at the dose mentioned above. The blood samples were collected under chloroform anaesthesia through retro orbital plexus in centrifugation tubes. The blood samples were incubated at $37^{\circ} \mathrm{C}$ for $1 \mathrm{~h}$ and centrifuged at $10000 \mathrm{rpm}$ for $15 \mathrm{~min}$ to collect serum. The serum samples were stored at $-20{ }^{\circ} \mathrm{C}$ till further use. Animals were sacrificed on the 120th day and subjected to estimation using the methods elaborated in the forthcoming section. Animal experiments were carried out as per the guidelines established by the Department of Animal welfare, Government of India, and was approved by the "institutional animal ethics committee (IAEC)” (approval no.: IAEC/SHIATS/ PA16III/SSPG19).

\section{Heart rate variability (HRV)}

The animals were anaesthetized using ketamine hydrochloride (100 $\mathrm{mg} \mathrm{kg}^{-1}$, i.m.) and diazepam ( $5 \mathrm{mg} \mathrm{kg}^{-1}$, i.m.) in combination on 119th day and subsequently mounted on a wax tray. The platinum hook electrodes were placed on the skin of the dorsal and ventral thorax to record the ECG signal. The electrodes were connected to Bio-amplifier (ML-136) (AD Instruments, Australia) and channel PowerLab (ML-826) (AD Instruments, Australia) to convert analogue to digital signals. The ECG signals were saved on the hard disk and analysed offline using Labchart Pro-8 (AD Instruments, Australia). HRV analysis was conducted on multiple segments of continuous ECG signals perceived in the preceding section. Firstly, all the raw signals were inspected manually to ensure that all the $\mathrm{R}$ waves are detected correctly. Subsequently, HR was calculated by plotting the number of $\mathrm{R}$ waves per unit time. Following the same, time and frequency domain parameters of HRV were calculated using the Lab chart Pro-8 (AD Instruments, Australia). ${ }^{19}$

\section{Carmine staining of whole mounts mammary gland}

Mammary gland tissues from each group were assessed for their morphological changes using carmine staining. The tissues were fixed by putting the slides into Carney's fixative solution for two days. Slides were washed with $70 \%$ ethanol and stained with a carmine alum solution for two days. Subsequently, stained tissues were rehydrated using increasing concentration of ethanol $(70 \%, 95 \%, 100 \%)$ followed by xylene for two days. Dehydrated slides were observed under a light microscope at $4 \times($ N120, BR Biochem Life Sciences, New Delhi, India). ${ }^{\mathbf{2 0}}$ Mammary gland differentiation (DF) was assessed by scoring the number of alveolar buds (ABs) type 1 and type 2. The score values (0-5) from AB1 and $\mathrm{AB} 2$ were added to a final DF score $(0-10) .{ }^{21}$

\section{Scanning electron microscopy (SEM)}

Fresh small unfixed pieces of the mammary gland tissues were taken from the each group. Tissue blocks were treated in eagle's balanced solution containing $100 \mu \mathrm{g} \mathrm{ml}^{-1}$ collagenase and 2.5 TRU (turbidity reduction unit) per $\mathrm{ml}$ of hyaluronidase containing $0.1 \mathrm{M}$ sodium phosphate buffer ( $\mathrm{pH}$ 5.3) and $0.15 \mathrm{M}$ sodium chloride $(1: 1)$ for $30 \mathrm{~min}$ at $37^{\circ} \mathrm{C}$. After digestion, the tissue blocks rinsed in the balanced solution, fixed in $4 \%$ glutaraldehyde in $0.1 \mathrm{M}$ cacodylate/ $\mathrm{HCl}$ buffer $(\mathrm{pH} 7.2)$ at room temperature for $3 \mathrm{~h}$ and placed in $8 \mathrm{~N} \mathrm{HCl}$ for $30-70 \mathrm{~min}$ at $60{ }^{\circ} \mathrm{C}$. After $\mathrm{HCl}$ digestion, the blocks were rinsed three times in distilled water to remove the acid. All the specimens were dehydrated with increasing acetone concentration $70 \%, 90 \%$, $95 \%$, and $100 \%$ for $45 \mathrm{~min}$ and examined under SEM at $1000 \times$ (JEOL JSM-6490LV). ${ }^{22}$

\section{Morphological evaluation}

Mammary gland tissues were appraised histopathologically using haematoxylin and eosin (H\&E) staining. The tissues were fixed in paraformaldehyde for overnight, succeeded by $70 \%$ isopropanol overnight. Tissues were further exposed to augmenting concentration of isopropanol (70\%, 90\%, and 100\%) 
consequently superseded by dehydration with $100 \%$ xylene. The tissues were embedded in paraffin wax and the blocks were prepared. $5 \mu \mathrm{m}$ sections were prepared using microtome followed by staining with H\&E. The sections were visualized and photographed at $40 \times$ using digital biological microscope (N120, BR-Biochem Life Sciences, New Delhi, India). ${ }^{23}$

\section{Biochemical estimation}

The mammary gland tissues $(10 \% \mathrm{w} / \mathrm{v})$ were homogenized in $0.15 \mathrm{M} \mathrm{KCl}$ and centrifuged at $10000 \mathrm{rpm}$. The supernatants were scrutinized for biochemical parameters including thiobarbituric acid reactive substances (TBAR's), superoxide dismutase (SOD), catalase, protein carbonyl and acetylcholine (Ach) using the methods established in our laboratory. ${ }^{24-27}$

\section{Caspase- 3 and caspase- 8}

Caspase- 3 and caspase- 8 fluorometric assays were performed using the methods elaborated in the literature. The assay was carried out in 96-well plate. Equal volumes of serum sample from both control and experimental animals were diluted with reaction buffer and DTT was added to a final concentration of $10 \mathrm{mM}$. To the reactant mixture $5 \mu \mathrm{l}$ of IETD-AFC/DEVD-AFC substrate was added and incubated for $1 \mathrm{~h}$ at $37^{\circ} \mathrm{C}$. Free AFC levels formed were measured in a plate reader with a $400 \mathrm{~nm}$ excitation and a $505 \mathrm{~nm}$ emission. The results of experimental samples were compared with control and expressed as fluorescence units per $\mathrm{mg}$ of protein. ${ }^{28,29}$

\section{Western blotting}

Protein samples were prepared from the mammary gland tissue through acetone precipitation and quantified by using the Bradford reagent. ${ }^{30}$ SDS-PAGE analysis was performed following the principles of Laemmli with slight modifications. ${ }^{31}$ Briefly, protein samples were mixed with sample buffer (125 mM TrisHCl, pH 6.8, 20\% glycerol, 4\% SDS, 0.05\% bromophenol blue, $10 \% 2$-mercaptoethanol). A $30 \mu \mathrm{g}$ of protein sample was allowed to resolve through $12 \%$ polyacrylamide gel using SDS-PAGE (GX-SCZ2+, Genetix Biotech Asia Pvt. Ltd, New Delhi). The proteins as resolved through SDS-PAGE were transferred to a PVDF membrane (IPVH 00010 Millipore, Bedford, MA USA) using semi-dry transfer (GX-ZY3, Genetix Biotech Asia Pvt. Ltd, New Delhi). Subsequently, membrane was blocked with 3\% BSA and $3 \%$ not fat milk in TBST for $2 \mathrm{~h}$ and incubated overnight with primary antibody against UCHL-1(MA1-83428) (1: 2000 dilution), (2876 cell signalling), COX (PA5-17614), NF-кBp65 (MA5-1616) (1 : 2000), BCL-xl (MA5-15142), BAD (SC-8044) (9292 cell signalling) and $\beta$-actin (MA5-15739-HRP) (Pierce, Thermo scientific) (1:300 dilution). The membrane was washed with TBST thrice and incubated with HRP conjugated rat antimouse secondary antibody (31 430, 1 : 5000 dilutions) (Pierce Thermo Scientific) at room temperature for $2 \mathrm{~h}$. The signals were detected using an enhanced chemiluminescence substrate (Western Bright ECL HRP substrate, Advansta, Melanopark, California, US). The quantification of protein was done through densiometric digital analysis of protein bands using Image $\mathrm{J}$ software. ${ }^{31,32}$

\section{Statistical analysis}

All data were presented as mean \pm SD and analysed by one-way ANOVA followed by Bonferroni test and for the possible significance identification between the various groups. ${ }^{*} p<$ $0.05, * * p<0.01$ and $* * * p<0.001$ were considered as statistically significant. Statistical analysis was performed using Graph pad prism software (5.02).

\section{Results}

The results revealed non-significant inflation in the $\mathrm{AB}(9.25 \pm$ $1.58)$ and lobule score $(2.63 \pm 1.06)$ with MNU treatment which was dose dependently curtailed down with the RFX treatment. Similar pattern of significant negating effects were evident in the RFX while scrutinizing the DF score in the whole mounts of the mammary gland (Table 1) (Fig. 1A-D). H\&E staining of the mammary gland tissue was evident with myoepithelial cells, cuboidal epithelial cells, loose connective tissue (LCT), dense connective tissue (DCT), lymphocytes, adipocytes and duct in the control animals. The MNU treatment distorted the normal architecture with loss of LCT and DCT along with myoepithelial cells, cuboidal epithelial cells. RFX treatment restored the normal architecture in the dose dependent manner (Fig. 1E-H). The mammary gland tissues were subsequently scrutinized through scanning electron microscopy. The control tissue was very well characterized with the presence capillary network along with collagenous covering. MNU treatment was recorded to have nodules formation representing cellular proliferation. Treatment with RFX helped to restore the collagenous covering and capillary network in the mammary gland (Fig. 1).

Non-significant changes were recorded in the TBAR's and GSH level after the MNU $(0.77 \pm 0.26 \mathrm{nM}$ of MDA per $\mathrm{mg}$ of protein and $0.40 \pm 0.02 \mathrm{mg} \%$ ) and RFX treatment afforded nonsignificant upregulation of the same. However, significant curtailment of the protein carbonyl level was perceived after the low dose RFX $\left(5.45 \pm 1.97 \mathrm{nM} \mathrm{ml}^{-1}\right)$ in comparison to $\mathrm{MNU}$ treated group $\left(12.24 \pm 1.80 \mathrm{nM} \mathrm{ml}^{-1}\right)$. The enzymatic defense of SOD ( $0.22 \pm 0.12$ units of SOD per $\mathrm{mg}$ of protein) and catalase (1.10 $\pm 0.02 \mathrm{nM}$ of $\mathrm{H}_{2} \mathrm{O}_{2}$ per min per $\mathrm{mg}$ of protein) was favorably regulated towards control by high dose RFX (Table 2).

Treatment with MNU up regulated the NFкBp65 expression in the mammary gland tissue and RFX $\left(25 \mathrm{mg} \mathrm{kg}^{-1}\right)$ afforded a significant curtailment of the same. The expression of the antiapoptotic markers (BCL-2 and BCL-xl) was significantly up regulated after the $\mathrm{MNU}$ treatment and $\mathrm{RFX}\left(25 \mathrm{mg} \mathrm{kg}{ }^{-1}\right.$ ) afforded significant down regulation of the same. In consonance to the antiapoptotic markers, the expression proapoptotic BAD was favorably up regulated by RFX $\left(25 \mathrm{mg} \mathrm{kg}^{-1}\right)$. The favorable regulation by the RFX towards the apoptotic marker was also evident through BAD/BCL-2 ratio, wherein RFX (25 $\mathrm{mg} \mathrm{kg}^{-1}$ ) observed significant increase. The above sets of observation were also endorsed, once scrutinized through the effector caspase 3 and caspase 8 . The RFX $\left(25 \mathrm{mg} \mathrm{kg}^{-1}\right)$ up regulated the levels of caspase 3 and caspase 8 in the MNU treated animals (Fig. 2). The overall tumor progression and prognosis by RFX was further scrutinized through the biological 
Table 1 Effect of MNU and RFX on differentiation of mammary gland ${ }^{a}$

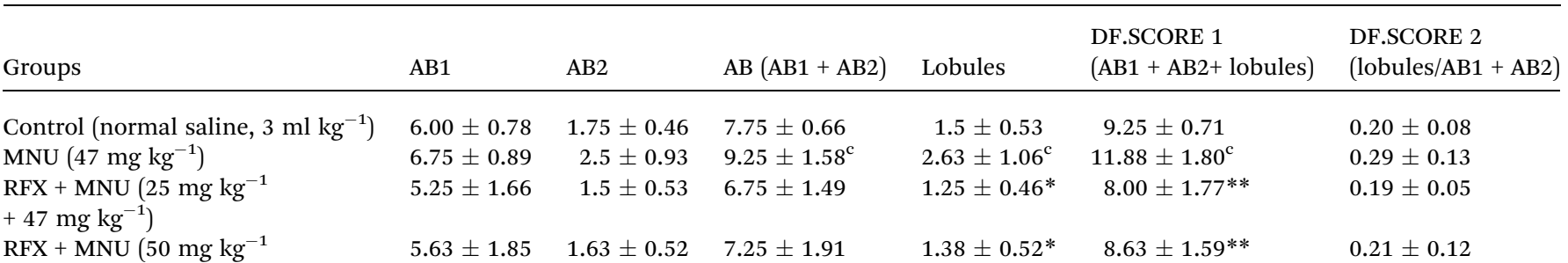

$\left.+47 \mathrm{mg} \mathrm{kg}^{-1}\right)$

${ }^{a}$ (Values are presented as mean $\pm \mathrm{SD}$ ), each group contains 6 animals. Comparisons were made on the basis of the one-way ANOVA followed by Bonferroni multiple test. All groups were compared to the toxic control group $\left({ }^{*} p<0.05,{ }^{* *} p<0.01,{ }^{* * *} p<0.001\right)$. All groups were compared to the control group $\left({ }^{\mathrm{a}} p<0.05,{ }^{\mathrm{b}} p<0.01,{ }^{\mathrm{c}} p<0.001\right)$.

markers like UCHL-1, COX-2 and autonomic dysfunction. RFX treatment non-significantly curtailed the expression of UCHL-1 in comparison to $\mathrm{MNU}$ treatment and COX-2 expression remained unaffected after the MNU or low dose of RFX treatment (Fig. 3).

The experimental animals were also scrutinized for the autonomic dysfunction as a prognostic marker for tumor progression. The study endorsed the increase in heart rate (HR) after the MNU treatment (494.95 $\pm 14.68 \mathrm{BPM}$ ) in comparison to control (415.4 $\pm 53.13 \mathrm{BPM})$. RFX $\left(25 \mathrm{mg} \mathrm{kg}{ }^{-1}\right)$ imparted a better restoration of $\mathrm{HR}(454.93 \pm 18.21 \mathrm{BPM})$. The $\mathrm{MNU}$ treatment was also evident with the QTc prolongation $(0.21 \pm 0.03 \mathrm{~S})$, which was restored to normal after RFX $(0.16 \pm$ $0.05 \mathrm{~S})$. QRS and QT interval of all the groups was not affected by
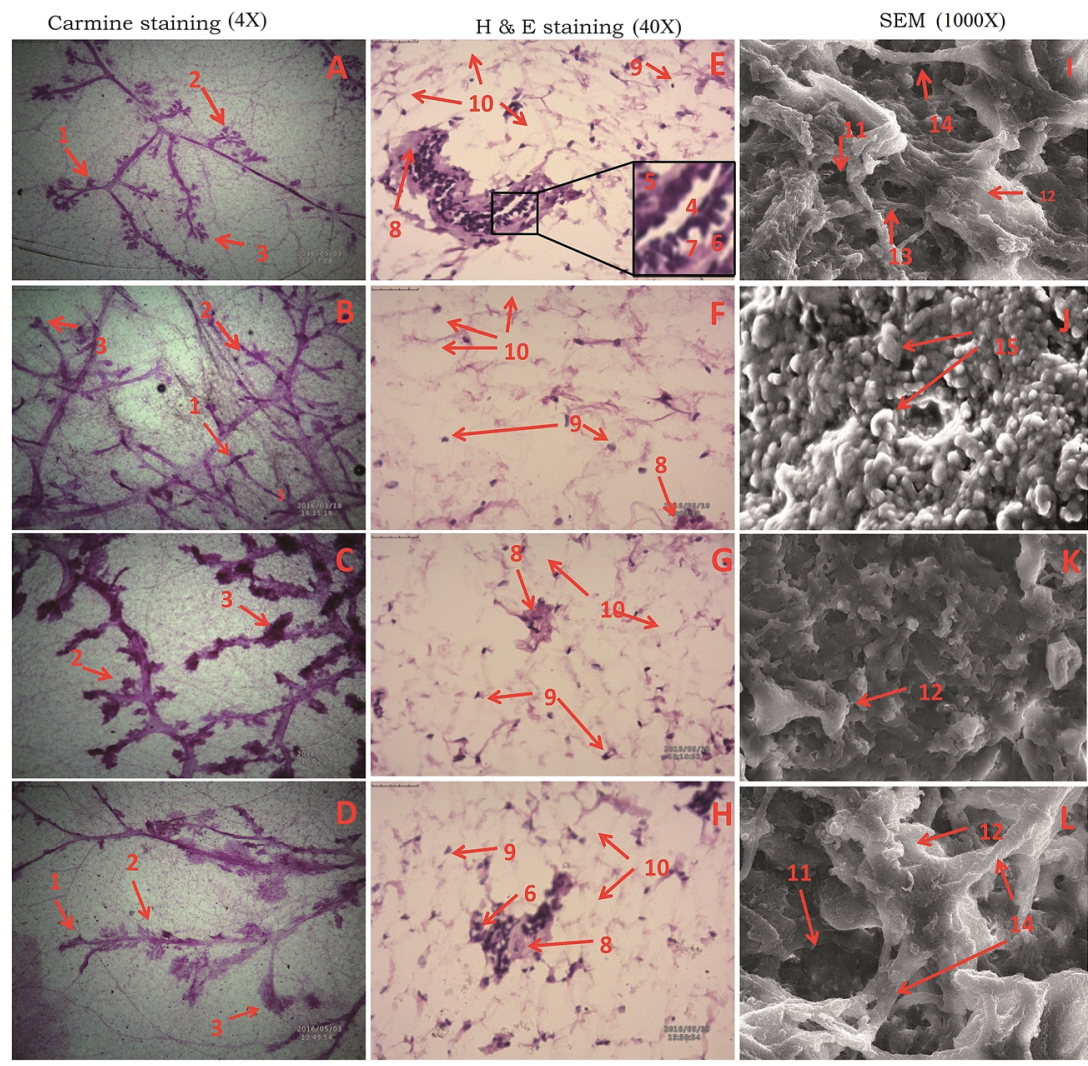

Fig. 1 Microscopic evaluation of the mammary gland tissue of the animal treated with RFX using carmine staining, H\&E staining, and SEM. Whole mount carmine staining of ductal epithelium reveals the presence of alveolar bud (1), alveolar bud (2) and lobules (3) in respective groups (A, B, C and D). The extent of alveolar budding and lobule formation are excessive in toxic group (B) which has been subsided with respective treatment groups ( $C$ and D). The images were captured under microscope with $4 \times$ magnification. Histopathological evaluation of the mammary gland tissue with H\&E staining in groups revealed the presence of duct (4), myoepithelial cells (5), cuboidal epithelial cells (6), loose connective tissue (7), dense connective tissue (8), lymphocytes (9), adipocytes (10) in control (E) and treatment groups (G and H). Absence of cell organelles and distorted cell morphology was found in toxic group (F). The images were captured under microscope with $40 \times$ magnification. Scanning electron microscopy of the mammary gland tissue $(1000 \times)$ of the groups control $(\mathrm{I})$, toxic control $(\mathrm{J})$, treatment group $(\mathrm{K}$ and $\mathrm{L})$ reveals the difference induct (11), collagen fibre (12), small capillary network (13), large blood vessels (14), nodules (15). 
either of the treatments (Table 3). The autonomic control was further scrutinized through the time and frequency domain HRV parameters. The ratio of lower frequency (LF) to higher frequency (HF) was decreased in MNU treated animals $(0.11 \pm$ $0.01)$ which was increased by the low dose RFX $(0.33 \pm 0.01)$ (Table 4) (Fig. 4). The autonomic dysfunction after the MNU treatment was also evident with the decreased levels of Ach $\left(923.97 \pm 27.72 \mathrm{nM} \mathrm{ml}^{-1}\right)$. Concomitant treatment with RFX dose dependently increased the Ach concentration with vice versa effect upon the plasma AchE levels.

\section{Discussion}

The present study demonstrated the effect of RFX against MNU induced mammary gland carcinogenesis in albino wistar rats. The mammary gland tissue was examined through whole mount preparation to study the small proliferative lesions represented by the increase in number of $\mathrm{AB}$ and lobules. $\mathrm{AB}$ and lobules represent the structure from which premalignant pathologic changes to ductal carcinoma and corresponds to the terminal ductal lobular units in human breast. ${ }^{33}$ Increase in $\mathrm{AB}$ number is directly correlated with the increased chances of developing malignancy and numerically represented through $\mathrm{DF}^{34}$ The MNU administration was evident with the increase in $\mathrm{AB}$ and DF score. Treatment with RFX afforded significant curtailment of the same, suggesting demarcating effect of RFX upon vascularization and subsequently angiogenesis in mammary gland tissue. ${ }^{14}$ The architecture of the mammary gland tissue was further scrutinized through the H\&E staining and SEM. The MNU administration was evident for loss to duct cuboidal epithelial, myoepithelial cells along with LCT, which are in corroboration with the previous reports. ${ }^{35}$ The corresponding SEM analysis revealed the loss of capillary network along with collagen fiber and development of nodules representing tumor lesions. ${ }^{36}$ The H\&E staining and SEM analysis confirmed the vascularization of mammary gland tissue by MNU as perceived through the whole mount preparation and is in line with the previous reports. Concomitant treatment with RFX afforded restoration of the duct, LCT, DCT and cuboidal epithelial cells when perceived through H\&E staining. On the similar lines, SEM analysis of the mammary gland tissue treated with RFX helped to restore the capillary network and collagen covering of the tissue. Studies have perceived a significant demarcating effect of RFX towards culminating the deleterious effects of MNU against mammary gland carcinoma in albino wistar rats.

Reactive oxygen species (ROS) generation and oxidative stress are a well-established testimony for the MNU induced carcinogenesis. ${ }^{37}$ Oxidative stress is defined as an imbalance between the generation and metabolism of ROS and reactive nitrogen species (RNS), surmounting to impaired cellular metabolism and changes in the intra and extracellular environmental conditions. ${ }^{38}$ Excessive ROS and RNS production could lead to DNA damage including mutations/deletions/ amplifications/rearrangements which can lead to defects in apoptosis. ${ }^{39}$ A delicate balance between the ROS/RNS production is mediated through exogenous or endogenous antioxidant 

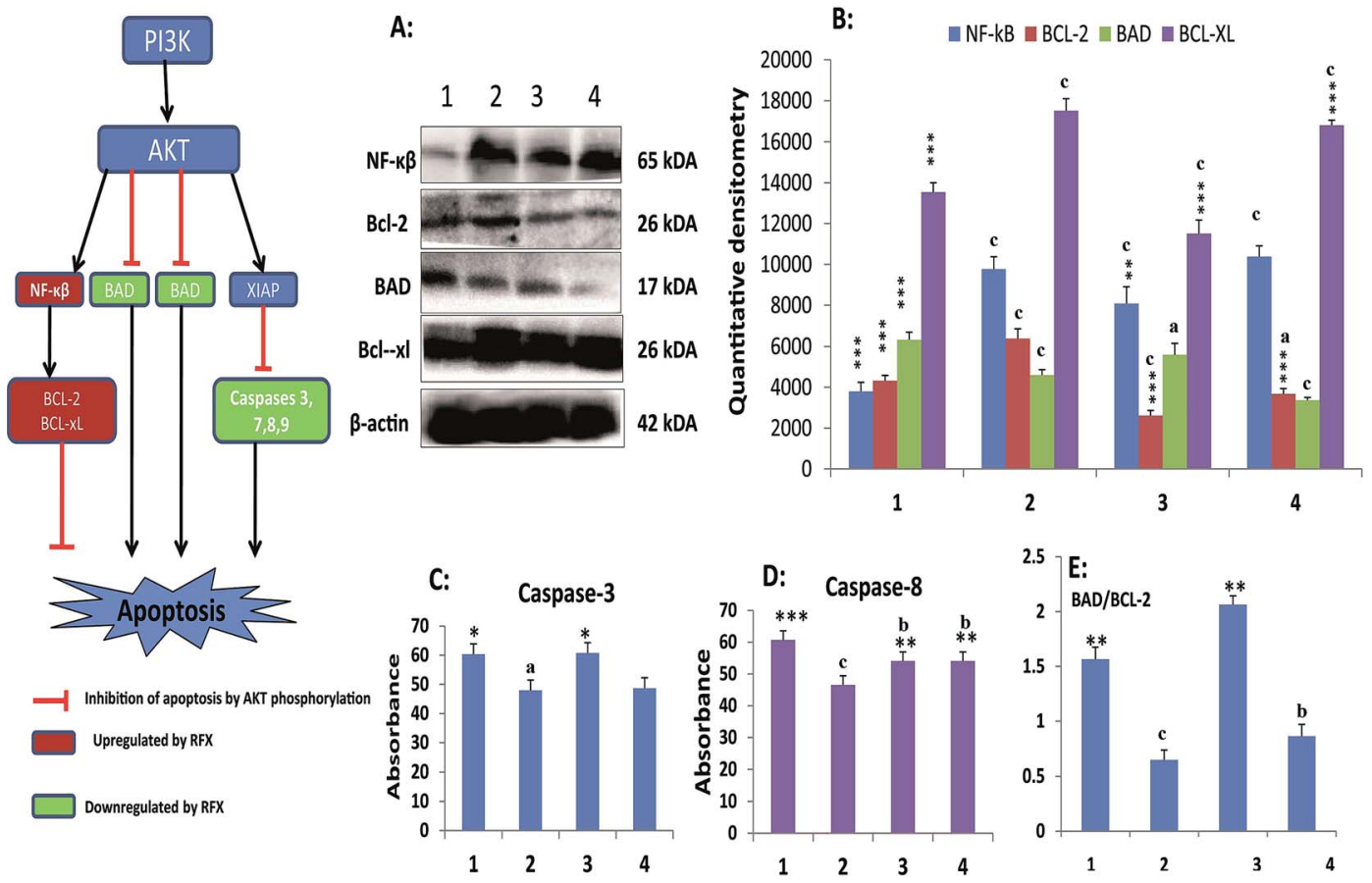

Fig. 2 Effect of RFX on cell death in ER+ mammary gland cancer. (A) RFX mediated activation of mitochondrial associated protein signalling in mammary gland cells. Protein extracted from control (1), toxic control (MNU, $47 \mathrm{mg} \mathrm{kg}^{-1}$ ) (2), RFX (25 mg kg ${ }^{-1}$ ) (3) and RFX (50 mg kg ${ }^{-1}$ ) (4) were subjected to immunoblotting of pro-apoptotic (BAD) and anti-apoptotic (BCL-2 and BCL-xl), and inflammatory marker (NF- $\kappa \beta)$. $\beta$-Actin was used as internal loading control. Each experiment was performed in triplicate; (B) respective quantitative densitometry graphs of immunoblots of the proteins; (C) and (D) regulation of caspase- 3 and caspase- 8 by RFX in serum samples respectively. The activity of caspase was determined by commercial fluorescence based kits; and (E) ratio of BAD/BCL-2 subjected to MNU and RFX treatment. The data were represented as mean \pm SD of three independent experimental protocols. Comparisons were made on the basis of the one-way ANOVA followed by Bonferroni multiple test. All groups were compared to the toxic control and control groups $\left(* / a p<0.05,{ }^{*} / \mathrm{b} p<0.01, * * * / c p<0.001\right)$.

defense regulated through enzymatic and non-enzymatic mechanisms. MNU treatment was evident with increase in lipid and protein peroxidation as perceived through increased TBAR's and protein carbonyl levels and thereby endorsing the ROS generation. The enzymatic antioxidant defense of SOD and
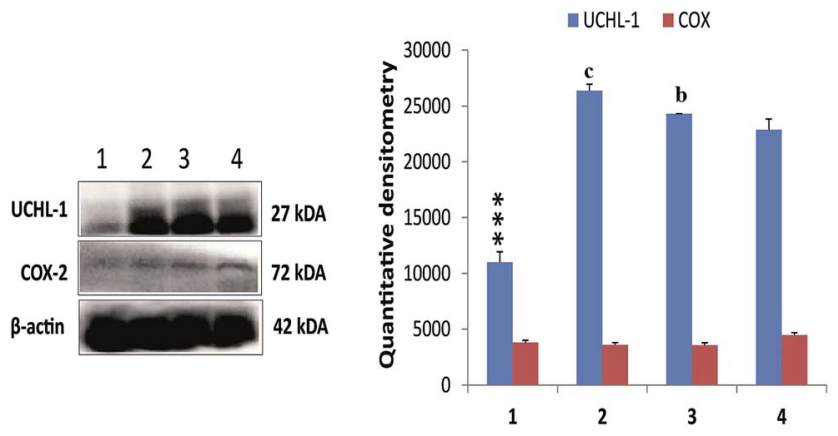

Fig. 3 Effect of RFX on prognostic markers of cancer progression in ER+ mammary gland cancer. Immunoblotting of respective individual group control (1), toxic control (MNU, $\left.47 \mathrm{mg} \mathrm{kg}^{-1}\right)(2), \operatorname{RFX}\left(25 \mathrm{mg} \mathrm{kg}^{-1}\right.$ ) (3) and RFX (50 $\mathrm{mg} \mathrm{kg}^{-1}$ ) (4) were subjected for UCHL-1 and COX-2. $\beta$ Actin was used as internal loading control. Each experiment was performed in triplicate. The data were represented as mean $\pm S D$. Comparisons were made on the basis of the one-way ANOVA followed by Bonferroni multiple test. All groups were compared to the toxic control and control groups $\left({ }^{* / a} p<0.05, * * / b p<0.01, * * * / c p<0.001\right)$. catalase were significantly up-regulated after MNU treatment and the same could be attributed to the feedback or activated enzymatic defense to counteract high circulating levels of ROS. It would be appropriate to notify that SOD, performs the dismutation of the $\mathrm{H}_{2} \mathrm{O}_{2}$ to $\mathrm{OH}$, which is further catalyzed to $\mathrm{H}_{2} \mathrm{O}$ and molecular $\mathrm{O}_{2}$ by catalase. Both the enzymes work in tandem to neutralize the ROS and a similar pattern of fold change in the $\mathrm{SOD} /$ catalase is expected and was perceived in the present experiment. The concomitant RFX treatment afforded significant curtailment in the products of lipid and protein peroxidation products along with up-regulation in the enzymatic levels of SOD and catalase. All in all, from the above one could derive significant negating effects of RFX against MNU induced cancer. However, the possible mechanisms beneath the same remain a stand still question and therefore authors considered it worth to study the effect of RFX on apoptotic markers.

Phosphoinositide-3 kinase/AKT (PI3K/AKT) signaling plays a vital role in cell survival and it has been implicated in various types of malignancies. ${ }^{40}$ PI3K/AKT performs as a prosurvival factor by inhibiting apoptotic signal including inhibition of proapoptotic family members (e.g. BAX, BAD); activation of NF$\kappa \beta$ transcription factor (promoting transcription of antiapoptotic genes, in particular and BCL-xl). Additionally AKT also activates prosurvival proteins XIAP (X-linked inhibitor of apoptosis protein) resulting in inhibition of caspases. ${ }^{41-44}$ All in all, PI3K/AKT phosphorylation inhibits the apoptotic signaling 
Table 3 Effect of RFX on ECG changes in MNU induced mammary gland carcinogenesis ${ }^{a}$

\begin{tabular}{|c|c|c|c|c|}
\hline ECG parameters & $\begin{array}{l}\text { Control } \\
\text { (normal saline, } \\
3 \mathrm{ml} \mathrm{kg}^{-1} \text {, p.o.) }\end{array}$ & $\begin{array}{l}\text { Toxic control } \\
\text { (MNU, } 47 \mathrm{mg} \mathrm{kg}^{-1} \text {, i.v.) }\end{array}$ & $\begin{array}{l}\mathrm{MNU}+\mathrm{RFX}\left(47 \mathrm{mg} \mathrm{kg}^{-1} \text { i.v. }\right) \\
+\left(25 \mathrm{mg} \mathrm{kg}^{-1} \text {, p.o. }\right)\end{array}$ & $\begin{array}{l}\mathrm{MNU}+\mathrm{RFX}\left(47 \mathrm{mg} \mathrm{kg}^{-1} \text { i.v. }\right) \\
+\left(50 \mathrm{mg} \mathrm{kg}^{-1} \text {, p.o. }\right)\end{array}$ \\
\hline RR interval (s) & $0.15 \pm 0.02$ & $0.18 \pm 0.02$ & $0.17 \pm 0.01$ & $0.22 \pm 0.04$ \\
\hline Heart rate (BPM) & $415.4 \pm 53.13^{*}$ & $494.95 \pm 14.68^{\mathrm{a}}$ & $454.93 \pm 18.21$ & $273.64 \pm 38.35^{* * *}$ \\
\hline PR interval (s) & $0.04 \pm 0.003^{*}$ & $0.05 \pm 0.002^{\mathrm{a}}$ & $0.05 \pm 0.005$ & $0.05 \pm 0.004$ \\
\hline$P$ duration (s) & $0.01 \pm 0.002$ & $0.02 \pm 0.002$ & $0.02 \pm 0.01$ & $0.02 \pm 0.002$ \\
\hline QRS interval (s) & $0.02 \pm 0.01$ & $0.02 \pm 0.01$ & $0.02 \pm 0.01$ & $0.02 \pm 0.002$ \\
\hline QT interval (s) & $0.06 \pm 0.02$ & $0.05 \pm 0.01$ & $0.06 \pm 0.02$ & $0.07 \pm 0.01$ \\
\hline QTc (s) & $0.16 \pm 0.04^{* *}$ & $0.21 \pm 0.03^{b}$ & $0.16 \pm 0.05^{* *}$ & $0.16 \pm 0.02^{* *}$ \\
\hline $\mathrm{JT}$ interval (s) & $0.04 \pm 0.02$ & $0.03 \pm 0.01$ & $0.05 \pm 0.02$ & $0.06 \pm 0.01$ \\
\hline$T$ peak tend interval $(\mathrm{s})$ & $0.03 \pm 0.01$ & $0.02 \pm 0.01$ & $0.03 \pm 0.01$ & $0.03 \pm 0.01$ \\
\hline$P$ amplitude $(\mathrm{mV})$ & $0.07 \pm 0.03$ & $0.10 \pm 0.04$ & $0.06 \pm 0.03$ & $0.08 \pm 0.03$ \\
\hline$Q$ amplitude (mV) & $-0.01 \pm 0.02^{*}$ & $0.05 \pm 0.09^{\mathrm{a}}$ & $0.01 \pm 0.02^{* * *}$ & $0.02 \pm 0.01^{* * *}$ \\
\hline$R$ amplitude (mV) & $1.20 \pm 0.36$ & $1.70 \pm 0.39$ & $1.20 \pm 0.23$ & $1.27 \pm 0.37$ \\
\hline$S$ amplitude (mV) & $-0.18 \pm 0.22$ & $-0.09 \pm 0.14$ & $-0.11 \pm 0.09$ & $-0.20 \pm 0.26$ \\
\hline ST segment (mV) & $-0.01 \pm 0.09$ & $-0.02 \pm 0.04$ & $0.03 \pm 0.04$ & $0.08 \pm 0.05^{*}$ \\
\hline$T$ amplitude (mV) & $0.25 \pm 0.12^{*}$ & $0.44 \pm 0.11^{\mathrm{a}}$ & $0.18 \pm 0.12^{\mathrm{a}}$ & $0.34 \pm 0.09 * * * a$ \\
\hline
\end{tabular}

${ }^{a}$ (Values are presented as mean $\pm \mathrm{SD}$ ), each group contains 6 animals. Comparisons were made on the basis of the one-way ANOVA followed by Bonferroni multiple test. All groups were compared to the toxic control group $\left({ }^{*} p<0.05,{ }^{* *} p<0.01,{ }^{* * *} p<0.001\right)$. All groups were compared to the control group $\left({ }^{\mathrm{a}} p<0.05,{ }^{\mathrm{b}} p<0.01,{ }^{\mathrm{c}} p<0.001\right)$.

through multidimensional pathways. It would be appropriate to mention that PI3K/AKT pathway is one among the most important signaling cascade in human breast cancer and a recent study has accorded that activation of PI3K/AKT pathway in the progression of MNU induced cancer. In accordance to the previous report, we recorded the activation PI3K/AKT signaling cascade endorsed by increased expression of NF- $\kappa \beta$ p 65 , BCL-XL and down regulation of the levels of $\mathrm{BAD}$, caspase 3 and caspase 8 ; subsequent to $\mathrm{MNU}$ treatment. Concomitant RFX treatment helped to down regulate the anti-apoptotic markers (NF- $\kappa \beta$ p65 and BCL-XL) and upregulated the pro-apoptotic signals (BAD, caspase 3 and caspase 8). It would be appropriate to remark that the low dose of RFX demonstrated more commendable regulation in comparison to high dose. The group of evidences derived through the above line of experiments gives a clear testimony for the efficacy of RFX against experimental carcinogenesis in albino wistar rats. The present observation is in line with the recent report, in fact adds to the small set of existing data that PXR activators can impart proliferative inhibition mediated through upregulation of proapoptotic markers. Authors would also like to pen down that the present report is the first in vivo report affirming the efficacy of PXR activators against an experimental model for breast cancer as warranted/suggested by the previous researchers. ${ }^{45}$

All in all, low dose of RFX was more effective to regulate the deleterious effects of MNU in comparison to high dose. It would be appropriate to pen down that despite being less effective, no adverse effects could be recorded even after the high dose of RFX. The less effectiveness of high dose could be attributed to the counterproductive effects of RFX. The present findings are in consonance to the previous report suggesting aggressive/high dose treatment produces the best short-term results but may counterproductive as observed in the present study. ${ }^{\mathbf{4 6}}$

Table 4 Effect of RFX on HRV changes in MNU induced mammary gland carcinogenesis ${ }^{a}$

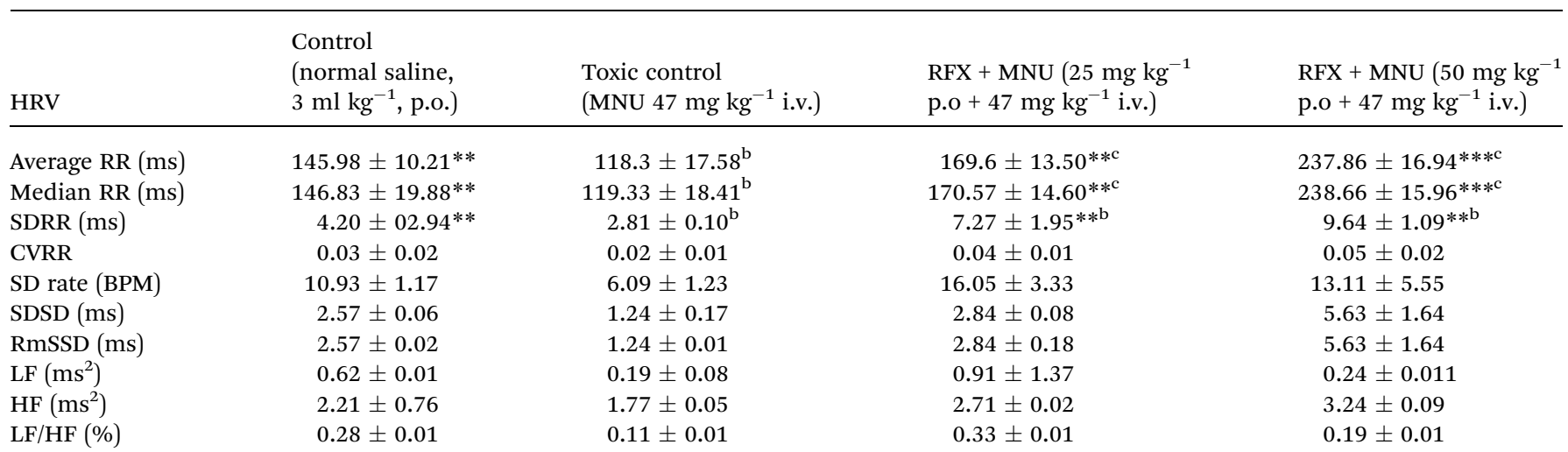

${ }^{a}$ (Values are presented as mean $\pm \mathrm{SD}$ ), each group contains 6 animals. Comparisons were made on the basis of the one-way ANOVA followed by Bonferroni multiple test. All groups were compared to the toxic control group $\left({ }^{*} p<0.05,{ }^{* *} p<0.01,{ }^{* * *} p<0.001\right)$. All groups were compared to the control group $\left({ }^{\mathrm{a}} p<0.05,{ }^{\mathrm{b}} p<0.01,{ }^{\mathrm{c}} p<0.001\right)$. 

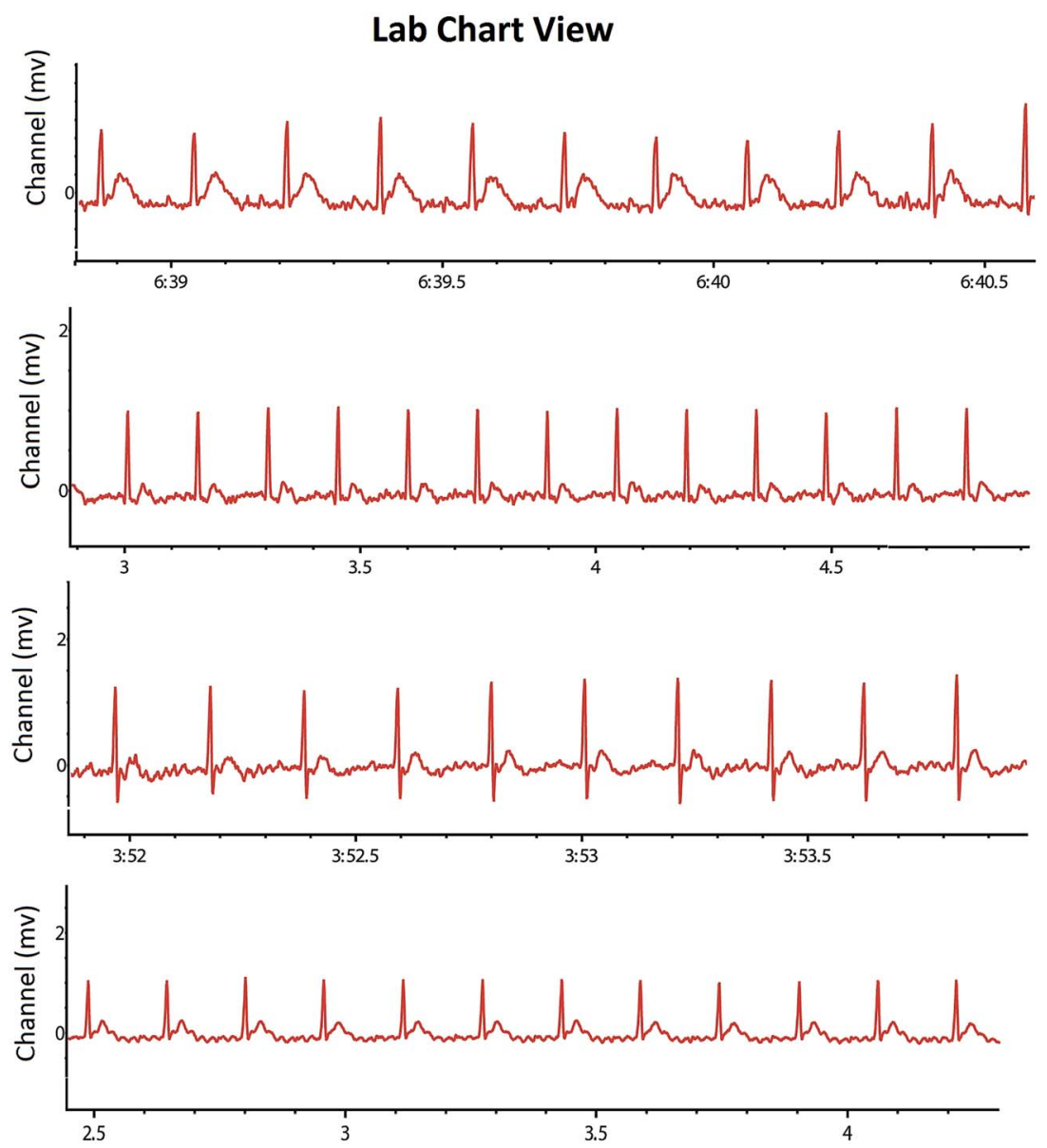

Fig. 4 Representative ECG recordings of the control, MNU and RFX treated animals. Recording of the heart rate variability of the individual group control (1), toxic control (MNU, $47 \mathrm{mg} \mathrm{kg}^{-1}$ ) (2), RFX (25 mg kg${ }^{-1}$ ) (3) and RFX (50 mg kg ${ }^{-1}$ ) (4). Increased HR and decreased HRV in the animals treated with MNU (2) and the same was restored in a treatment group (3 and 4) similar to control (1).

Integrated multidimensional prognostic biomarkers approach is always preferred/utilized to define the effectiveness of the proposed therapy. Henceforth, authors considered it worth to evaluate the COX-2, UCHL-1 and markers of autonomic dysfunction in the present study to further validate the efficacy of PXR activation through RFX. UCHL-1 is a tumor suppressor gene and has gained importance for its diagnostic and antimetastatic potential, particularly in case of breast cancer due to its deubiquitinating effect upon hypoxia-inducible factor- $1 \alpha$ (HIF-1 $\alpha) .{ }^{47}$ Previously, we have reported the up-regulated levels of UCHL-1 in case of MNU induced carcinogenesis and similar observation was taken on record in the present study as well. RFX at the high dose was able to nudge down the UCHL-1 levels. The association between inflammation, cancer and COX-2 is well established. Plethora of scientific literature, including from our own laboratory has endorsed significant up-regulation of COX-2 in MNU induced mammary gland carcinoma. However we could not observe any change in the COX-2 expression in either of the groups. Authors would like to submit that appropriate control was incorporated during the experiment to avoid misidentification of COX-2. However, the present observation is beyond the scope of present manuscript.
Autonomic dysfunction represents of autonomic control usually associated with sympathetic over activity and parasympathetic down regulation. The autonomic dysfunction associated cardiovascular risk among the early breast cancer and breast cancer survivors is a well reported phenomenon. ${ }^{48}$ The interrelationship between the sympathetic and parasympathetic nervous system can be read using HRV. Therefore to have a broader prospect of the present study authors evaluated the HRV of the animals treated with MNU and subsequently RFX. Most of the antineoplastic therapy has been reported to be associated with autonomic dysfunction in breast cancer patients. ${ }^{49}$ The poor autonomic control has been reported to be associated with increased HR and decreased HRV in the early breast cancer and survivors of breast cancer patients and MNU treatment was evident for the similar pattern of increased HR and decreased HRV. ${ }^{50}$ The increased HR and decreased HRV, endorses the autonomic dysfunction in the animals treated with MNU and is in corroboration with the previous clinical reports of autonomic dysfunction in early breast cancer cases.51 The autonomic dysfunction in the animals treated with MNU was also supported by the fact that we observed significant decline in the Ach levels after MNU 
treatment. The decrease in Ach represents parasympathetic down regulation and could be associated with sympathetic overactivity. ${ }^{\mathbf{1 7}}$ However, concomitant RFX treatment afforded a significant increase in the Ach level. The said observation is a clear indicative of the restoration of the autonomic function and therefore suggests a good prognosis by RFX.

To the best of our knowledge the present report is first to elaborate the prognostic relationship between carcinogenesis and autonomic dysfunction in experimental model. All in all, RFX demonstrated good prognostic valve in the management of experimental carcinogenesis through restoration of UCHL-1 and regulating the autonomic dysfunction.

\section{Authors contributions}

SG and PS performed the experimental work, performed the calculations, organised the data; JKR performed the electrocardiographic studies; SR and MS performed the western blotting; RKY, and UD performed the SEM, histopathological studies; PSG and SAS performed the statistical analysis; GK perceived the idea, designed and supervised the overall study, prepared and proof read the final manuscript.

\section{Conflicts of interest}

Authors declare no competing interest.

\section{Acknowledgements}

The author would like to thanks University Grants Commission, Government of India for granting senior research fellowship to MS, JKR and SG. Authors are also thankful to Department of Science and Technology, Government of India for granting senior research fellowship SR.

\section{References}

1 G. Laustsen and L. Wimmett, Drug Approval Highlights FDA Update, Nurse Pract., 2005, 30(2), 14-29.

2 H. DuPont, Rifaximin: an antibiotic with important biologic effects, Mini-Rev. Med. Chem., 2016, 16(3), 200-205.

3 G. Esposito, S. Gigli, L. Seguella, N. Nobile, A. D'Alessandro and M. Pesce, Rifaximin, a non-absorbable antibiotic, inhibits the release of pro-angiogenic mediators in colon cancer cells through a pregnane $\mathrm{X}$ receptor-dependent pathway, Internet J. Oncol., 2016, 49(2), 639-645.

4 Y. Jia, N. Viswakarma and J. K. Reddy, Med1 subunit of the mediator complex in nuclear receptor-regulated energy metabolism, liver regeneration, and hepatocarcinogenesis, Gene Expression, 2016, 16(2), 63-75.

5 I. Koutsounas, S. Theocharis, E. Patsouris and C. Giaginis, Pregnane $\mathrm{X}$ receptor (PXR) at the crossroads of human metabolism and disease, Curr. Drug Metab., 2013, 14(3), 341-350.

6 P. Pavek, Pregnane X receptor (PXR)-mediated gene repression and cross-talk of PXR with other nuclear receptors via coactivator interactions, Front. Pharmacol., 2016, 25(7), 456.

7 D. Robbins and T. Chen, Tissue-specific regulation of pregnane $\mathrm{X}$ receptor in cancer development and therapy, Cell Biosci., 2014, 4(1), 17.

8 C. T. Brewer and T. Chen, PXR variants: the impact on drug metabolism and therapeutic responses, Acta Pharm. Sin. B, 2016, 6(5), 441-449.

9 L. Mo and J. He, Nuclear hormone receptors PXR and CAR and metabolic diseases, Horm. Mol. Biol. Clin. Invest., 2014, 19(2), 129-140.

$10 \mathrm{~J}$. Yan and W. Xie, A brief history of the discovery of PXR and CAR as xenobiotic receptors, Acta Pharm. Sin. B, 2016, 6(5), 450-452.

11 D. Kotiya, B. Jaiswal, S. Ghose, R. Kaul, K. Datta and R. K. Tyagi, Role of PXR in Hepatic Cancer: Its Influences on Liver Detoxification Capacity and Cancer Progression, PLoS One, 2016, 11(10), e0164087.

12 H. Masuyama, K. Nakamura, E. Nobumoto and Y. Hiramatsu, Inhibition of pregnane $\mathrm{X}$ receptor pathway contributes to the cell growth inhibition and apoptosis of anticancer agents in ovarian cancer cells, Internet J. Oncol., 2016, 49(3), 1211-1220.

13 S. R. Pondugula, P. Pavek and S. Mani, Pregnane X Receptor and Cancer: Context-Specificity is Key, Nucl. Receptor Res., 2016, $12,3$.

14 N. Zucchini, G. de Sousa, B. Bailly-Maitre, J. Gugenheim, R. Bars, G. Lemaire, et al., Regulation of Bcl-2 and Bcl-xL anti-apoptotic protein expression by nuclear receptor PXR in primary cultures of human and rat hepatocytes, $B B A$, Biochim. Biophys. Acta, Mol. Cell Res., 2005, 1745(1), 48-58.

15 J. Zhou, M. Liu, Y. Zhai and W. Xie, The antiapoptotic role of pregnane $\mathrm{X}$ receptor in human colon cancer cells, Mol. Endocrinol., 2008, 22(4), 868-880.

16 H. Masuyama, H. Nakatsukasa, N. Takamoto and Y. Hiramatsu, Down-regulation of pregnane $\mathrm{X}$ receptor contributes to cell growth inhibition and apoptosis by anticancer agents in endometrial cancer cells, Mol. Pharmacol., 2007, 72(4), 1045-1053.

17 S. Revathidevi, R. Sudesh, V. Vaishnavi, M. Kaliyanasundaram, K. G. MaryHelen, G. Sukanya and A. K. Munirajan, Screening for the $3^{\prime}$ UTR Polymorphism of the PXR Gene in South Indian Breast Cancer Patients and its Potential role in Pharmacogenomics, Asian Pac. J. Cancer Prev., 2016, 17(8), 3971-3977.

18 S. Verma, M. M. Tabb and B. Blumberg, Activation of the steroid and xenobiotic receptor, SXR, induces apoptosis in breast cancer cells, BMC Cancer, 2009, 9(1), 1.

19 T. Shintaku, T. Ohba, H. Niwa, T. Kushikata, K. Hirota, K. Ono, Y. Matsuzaki, T. Imaizumi, K. Kuwasako, D. Sawamura and M. Murakami, Effects of propofol on electrocardiogram measures in mice, J. Pharmacol. Sci., 2014, 126(4), 351-358.

20 J. Russo, B. A. Gusterson, A. E. Rogers, I. H. Russo, S. R. Wellings and M. J. VanZwieten, Comparative study of human and rat mammary tumorigenesis, Pathol Rev, Springer, 1990, pp. 217-251. 
21 C. Manral, S. Roy, M. Singh, S. Gautam, R. K. Yadav, J. K. Rawat, U. Devi, M. N. Ansari, S. A. Saeedan and G. Kaithwas, Effect of $\beta$-sitosterol against methyl nitrosourea-induced mammary gland carcinoma in albino rats, BMC Complementary Altern. Med., 2016, 16(1), 260.

22 T. Nagato, H. Yoshida, A. Yoshida and Y. Uehara, A scanning electron microscope study of myoepithelial cells in exocrine glands, Cell Tissue Res., 1980, 209(1), 1-10.

23 D. S. Murray, L. A. Ruble, H. Willis and C. A. Molloy, Parent and teacher report of social skills in children with autism spectrum disorders, Lang. Speech Hear Serv. Sch., 2009, 40(2), 109-115.

24 G. Kaithwas and D. K. Majumdar, In vitro antioxidant and in vivo antidiabetic, antihyperlipidemic activity of linseed oil against streptozotocin-induced toxicity in albino rats, Eur. J. Lipid Sci. Technol., 2012, 114(11), 1237-1245.

25 G. Kaithwas, A. Mukherjee, A. Chaurasia and D. K. Majumdar, Antiinflammatory, analgesic and antipyretic activities of Linum usitatissimum L. (flaxseed/linseed) fixed oil, Indian J. Exp. Biol., 2011, 49, 932-938.

26 G. Kaithwas Dubey, D. Bhatia, A. D. Sharma and K. Pillai, Reversal of sodium nitrite induced impairment of spontaneous alteration by Aloe vera gel: Involvement of cholinergic system, Pharmacologyonline, 2007, 3, 428-437.

27 A. Z. Reznick and L. Packer, [38] Oxidative damage to proteins: Spectrophotometric method for carbonyl assay, Methods Enzymol., 1994, 233, 357-363.

28 J. Liphardt, S. Dumont, S. B. Smith, I. Tinoco and C. Bustamante, Equilibrium information from nonequilibrium measurements in an experimental test of Jarzynski's equality, Science, 2002, 296(5574), 1832-1835.

29 B. R. Celli, W. MacNee, A. Agusti, A. Anzueto, B. Berg, A. S. Buist, et al., Standards for the diagnosis and treatment of patients with COPD: a summary of the ATS/ ERS position paper, Eur. Respir. J., 2004, 23(6), 932-946.

$30 \mathrm{~N}$. Sharma and Y. Ahmad, An effective method for the analysis of human plasma proteome using twodimensional gel electrophoresis, J. Proteomics Bioinf., 2011, 2009.

31 U. K. Laemmli, Cleavage of structural proteins during the assembly of the head of bacteriophage T4, Nature, 1970, 227, 680-685.

32 H. Towbin, T. Staehelin and J. Gordon, Electrophoretic transfer of proteins from polyacrylamide gels to nitrocellulose sheets: procedure and some applications, Proc. Natl. Acad. Sci. U. S. A., 1979, 76(9), 4350-4354.

33 T. L. Mastracci, F. I. Boulos, I. L. Andrulis and W. L. Lam, Genomics and premalignant breast lesions: clues to the development and progression of lobular breast cancer, Breast Cancer Res., 2007, 9(6), 1.

34 I. H. Russo and J. Russo, Mammary gland neoplasia in longterm rodent studies, Environ. Health Perspect., 1996, 104(9), 938.

35 R. D. Cardiff and S. R. Wellings, The comparative pathology of human and mouse mammary glands, J. Mammary Gland Biol. Neoplasia, 1999, 4(1), 105-122.

36 T. Yasugi, T. Kaido and Y. Uehara, Changes in density and architecture of microvessels of the rat mammary gland during pregnancy and lactation, Arch. Histol. Cytol., 1989, 52(2), 115-122.

37 A. Rani, S. Roy, M. Singh, U. Devi, R. K. Yadav, S. Gautam, J. K. Rawat, M. N. Ansari, S. A. Saeedan, A. Prakash and G. Kaithwas, $\alpha$-Chymotrypsin regulates free fatty acids and UCHL-1 to ameliorate $N$-methyl nitrosourea induced mammary gland carcinoma in albino wistar rats, Inflammopharmacology, 2016, 24(5), 277-286.

38 B. Halliwell, and J. M. Gutteridge, Free radicals in biology and medicine: Oxford University Press, USA, 2015.

$39 \mathrm{H}$. Wiseman and B. Halliwell, Damage to DNA by reactive oxygen and nitrogen species: role in inflammatory disease and progression to cancer, Biochem. J., 1996, 313(Pt 1), 17.

40 J. A. F. Vara, E. Casado, J. de Castro, P. Cejas, C. Belda-Iniesta and M. González-Barón, PI3K/Akt signalling pathway and cancer, Cancer Treat. Rev., 2004, 30(2), 193-204.

41 Y. Chen, Y. Tang, S. Chen and D. Nie, Regulation of drug resistance by human pregnane $\mathrm{X}$ receptor in breast cancer, Cancer Biol. Ther., 2009, 8(13), 1265-1272.

42 R. C. Richie and J. O. Swanson, Breast cancer: a review of the literature, J. Insur. Med., 2003, 35(2), 85-101.

43 H. E. M. zu Schwabedissen, R. G. Tirona, C. S. Yip, R. H. Ho and R. B. Kim, Interplay between the nuclear receptor pregnane $\mathrm{X}$ receptor and the uptake transporter organic anion transporter polypeptide 1A2 selectively enhances estrogen effects in breast cancer, Cancer Res., 2008, 68(22), 9338-9347.

44 Y. M. Shah, X. Ma, K. Morimura, I. Kim and F. J. Gonzalez, Pregnane $\mathrm{X}$ receptor activation ameliorates DSS-induced

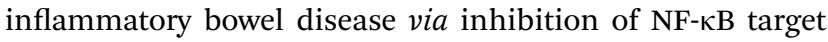
gene expression, Am. J. Physiol.: Gastrointest. Liver Physiol., 2007, 292(4), G1114-G1122.

45 N. A. Venier, Capsaicin as a Novel Chemopreventive and Therapeutic Option for Prostate Cancer, University of Toronto, 2015.

46 C. A. Dinarello, Why not treat human cancer with interleukin-1 blockade?, Cancer Metastasis Rev., 2010, 29(2), 317-329.

47 Y. Goto, L. Zeng, C. J. Yeom, Y. Zhu, A. Morinibu, K. Shinomiya, et al., UCHL1 provides diagnostic and antimetastatic strategies due to its deubiquitinating effect on HIF-1 $\alpha$, Nat. Commun., 2015, 6, 6153.

$48 \mathrm{~S}$. Julius and S. Nesbitt, Sympathetic overactivity in hypertension a moving target, Am. J. Hypertens., 1996, 9(S4), 113S-120S.

49 D. C. Doll, Q. S. Ringenberg and J. Yarbro, Vascular toxicity associated with antineoplastic agents, J. Clin. Oncol., 1986, 4(9), 1405-1417.

50 E. L. Worthington Jr, C. V. O. Witvliet, P. Pietrini and A. J. Miller, Forgiveness, health, and well-being: A review of evidence for emotional versus decisional forgiveness, dispositional forgivingness, and reduced unforgiveness, $J$. Behav. Med., 2007, 30(4), 291-302.

51 E. Caro-Morán, C. Fernández-Lao, N. Galiano-Castillo, I. Cantarero-Villanueva, M. Arroyo-Morales and L. DíazRodríguez, Heart Rate Variability in Breast Cancer Survivors After the First Year of Treatments A CaseControlled Study, Biol. Res. Nurs., 2016, 18(1), 43-49. 